\title{
Impact of prehabilitation during neoadjuvant chemotherapy and interval cytoreductive surgery on ovarian cancer patients: a pilot study
}

Ester Miralpeix ${ }^{1,2^{*}}$, Josep-Maria Sole-Sedeno ${ }^{1,2}$, Cristina Rodriguez-Cosmen ${ }^{3}$, Alvaro Taus ${ }^{4,5}$, Maria-Dolors Muns ${ }^{6}$, Berta Fabregó ${ }^{1}$ and Gemma Mancebo ${ }^{1,2}$

\begin{abstract}
Background: Cytoreductive surgery followed by systemic chemotherapy is the standard of treatment in advanced ovarian cancer where feasible. Neoadjuvant chemotherapy (NACT) followed by surgery is applicable where upfront cytoreductive surgery is not feasible because of few certain reasons. Nevertheless, surgical interventions and the chemotherapy itself may be associated with postoperative complications usually entailing slow postoperative recovery. Prehabilitation programs consist of the patient's preparation before surgery to improve the patient's functional capacity. The aim of this study was to evaluate the impact of a prehabilitation program during neoadjuvant treatment and interval cytoreductive surgery for ovarian cancer patients.
\end{abstract}

Methods: A retrospective observational pilot study of patients with advanced ovarian cancer treated with NACT and interval cytoreductive surgery was conducted. The prehabilitation group received a structured intervention based on physical exercise, nutritional counseling, and psychological support. Nutritional parameters were assessed preoperatively and postoperatively, and functional parameters and perioperative and postoperative complications were also recorded.

Results: A total of 29 patients were included in the study: 14 in the prehabilitation group and 15 in the control group. The patients in the prehabilitation program showed higher mean total protein levels in both preoperative (7.4 vs. 6.8, $p=0.004$ ) and postoperative (4.9 vs. $4.3, p=0.005$ ) assessments. Up to $40 \%$ of controls showed intraoperative complications vs. $14.3 \%$ of patients in the prehabilitation group, and the requirement of intraoperative blood transfusion was significantly lower in the prehabilitation group ( $14.3 \%$ vs. $53.3 \%, p=0.027)$. The day of the first ambulation, rate of postoperative complications, and length of hospital stay were similar between the groups. Finally, trends towards shorter time between diagnosis and interval cytoreductive surgery $(p=0.097)$ and earlier postoperative diet restart $(p$ $=0.169$ ) were observed in the prehabilitation group.

Conclusion: Prehabilitation during NACT in women with ovarian cancer candidates to interval cytoreductive surgery may improve nutritional parameters and thereby increase postoperative recovery. Nevertheless, the results of this pilot study are preliminary, and further studies are needed to determine the clinical impact of prehabilitation programs.

\footnotetext{
*Correspondence: ester.miralpeix@gmail.com

${ }^{2}$ Universitat Pompeu Fabra, Barcelona, Spain

Full list of author information is available at the end of the article
}

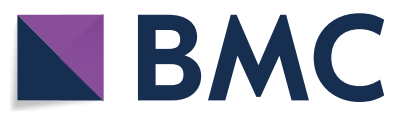

(c) The Author(s) 2022. Open Access This article is licensed under a Creative Commons Attribution 4.0 International License, which permits use, sharing, adaptation, distribution and reproduction in any medium or format, as long as you give appropriate credit to the original author(s) and the source, provide a link to the Creative Commons licence, and indicate if changes were made. The images or other third party material in this article are included in the article's Creative Commons licence, unless indicated otherwise in a credit line to the material. If material is not included in the article's Creative Commons licence and your intended use is not permitted by statutory regulation or exceeds the permitted use, you will need to obtain permission directly from the copyright holder. To view a copy of this licence, visit http://creativecommons.org/licenses/by/4.0/. The Creative Commons Public Domain Dedication waiver (http://creativeco mmons.org/publicdomain/zero/1.0/) applies to the data made available in this article, unless otherwise stated in a credit line to the data. 
Keywords: Prehabilitation, Neoadjuvant chemotherapy, Interval cytoreductive surgery, Ovarian cancer

\section{Introduction}

Advanced ovarian cancer is a complex and challenging disease whose treatment requires a multimodal approach [1]. Primary treatment consists of optimal primary cytoreductive surgery followed by systemic chemotherapy. In patients unsuitable for primary cytoreductive surgery due to advanced age, frailty, poor performance status, comorbidities, or disease that is unlikely to be optimally cytoreduced, neoadjuvant chemotherapy (NACT) followed by interval cytoreductive surgery should be considered [2,3]. Therefore, cytoreductive surgery after NACT is often undertaken in patients who are physically, nutritionally, and/or psychologically affected. The aim of NACT is to achieve radiological and clinical improvement to increase the likelihood of optimal cytoreduction at interval cytoreductive surgery $[4,5]$.

Many patients with advanced ovarian cancer present with abdominal disease that can lead to malnutrition, and some patients present physiological effects of peripheral muscle wasting, decreased exercise tolerance and fatigue, and psychological morbidity for anxiety of a potentially terminal cancer diagnosis [6]. Surgery is an aggressive procedure that disrupts the physiologic status and triggers a general stress response, altering hormonal, metabolic, immunologic, and neurological functions, and NACT treatment may also affect the physiologic status and body function [7]. In particular, cytoreductive surgery usually requires peritonectomy, lymphadenectomy, visceral resection, and gastrointestinal anastomoses $[8,9]$. Therefore, it seems appropriate to restore the baseline status of ovarian cancer patients before exposition to another acute stressor such as surgery and especially after NACT. The period on NACT before interval cytoreductive surgery offers a window of opportunity to improve the patient's functional capacity or to restore its capacity to baseline levels $[10,11]$.

Prehabilitation programs consist of the patient's preparation between diagnosis and surgery to improve functional capacity and metabolic reserves before the intervention, resulting in a reduction of perioperative complications. Multimodal prehabilitation may include exercise, nutritional counseling, psychological support, and optimization of underlying conditions, as well as cessation of negative health behaviors such as alcohol or tobacco consumption [12]. Emerging evidence suggests that multimodal prehabilitation programs in major cancer surgeries have a positive impact on the patients' outcomes $[13,14]$. Therefore, it would be expected that a multimodal prehabilitation program during NACT before interval cytoreductive surgery in patients with advanced ovarian cancer could enhance patients' functional capacity. With this purpose, we formed a multidisciplinary team to implement a pilot prehabilitation program to support gynecologic oncology patients. The aims of this study were to evaluate our initial experience and impact of a multimodal prehabilitation program in advanced-stage ovarian cancer patients undergoing interval cytoreductive surgery.

\section{Materials and methods Design and subjects}

A retrospective pilot observational study of patients undergoing interval cytoreductive surgery for ovarian cancer was conducted at the Hospital del Mar Barcelona between January 2015 and June 2020.

Eligible patients were women diagnosed with advanced ovarian cancer undergoing interval cytoreductive surgery after standardized 3 cycles of NACT with carboplatin and paclitaxel. In previous interval cytoreductive surgery, all patients were evaluated through laparoscopic approach and computed tomography scan to consider optimally resectable disease by a multidisciplinary team. The exclusion criteria were inability to give informed consent, having non-resectable disease, inability to perform exercises with locomotor limitations, cognitive deterioration impeding adherence to the program, patients who declined surgery or NACT, or those who received non-standard NACT. The prehabilitation program was implemented in January 2018, and the first patients that followed the prehabilitation program were consecutively included in this pilot study. Patients treated before this date were used as a control group.

\section{Prehabilitation intervention}

The prehabilitation program was developed by a multidisciplinary team of gynecologists, anesthesiologists, physiotherapists, dieticians, psychologists, and geriatricians. The prehabilitation group received a structured intervention including physical exercise recommendations, nutritional counseling, and psychological support. This program was extensively described in a previous publication [15]. Briefly, all patients included in the prehabilitation program received recommendations for daily exercise practice, nutritional counseling based on homemade recipes of protein supplementation and psychological support, and a preoperative carbohydrate loading and an inspiratory threshold-loading device in our consultation. Patients in the prehabilitation program 
received perioperative care, following the guidelines of the Enhanced Recovery After Surgery (ERAS) program, which has been the standard of surgical approach for our patients since 2015 [16, 17]. The control group received standard of care, and no specific intervention before surgery was administered.

The length of the prehabilitation program was not fixed and depended on the patient's status, tumor type, and extension. In addition, the duration also depended on the time period before surgery, which was modulated by NACT tolerance and toxicity, organizational aspects of healthcare providers, and by type of surgical intervention.

\section{Variables and outcomes}

Demographic and clinical baseline information was collected retrospectively from medical registries. Nutritional status was evaluated by total serum protein, albumin, hemoglobin, and prealbumin levels. Measurements were recorded at diagnosis, just before the interval surgery, $48-72 \mathrm{~h}$ post-surgery, and 1 month after surgery. The main surgical, intraoperative, and postoperative parameters reported included peri- and postoperative complications, postoperative pain, length of hospital stay, days of intensive care unit (ICU) stay, day of the first ambulation, and readmission rates. Complications were classified according to Clavien-Dindo classification (grades I-V) [18]. The complexity of the surgical procedure was classified using Aletti's surgical complexity score (SCS), based on the number and the complexity of the surgical procedures performed [19].

\section{Statistical methods}

Statistical analysis was performed using SPSS 21.0 (Chicago, IL, USA) assuming a statistically significant level of $5 \%(p<0.05)$. Participant demographic and clinical characteristics were summarized using descriptive statistics. Continuous variables were reported as mean (range) or mean \pm standard deviation (SD) when indicated, and categorical variables were reported as frequency and percentage (\%). Pearson's chi-square test or Fisher exact test was used to compare categorical variables, and Student's $t$-test or non-parametric Mann-Whitney test was used for continuous variables, when appropriate.

\section{Ethical considerations}

The study was evaluated and approved by the institutional ethics committee (Institutional Review Board Project No. 2017/7770/I). All participants provided a written informed consent.

\section{Results}

A total of 29 patients undergoing interval cytoreductive surgery for ovarian cancer were included in the study. Overall, 15 patients were included in the control group and 14 in the prehabilitation group. The mean age of patients was $64.5 \pm 8.8$ years (range $51-83$ ). Baseline demographic and clinical characteristics of the study population are shown in Table 1. There were no significant differences in age, clinical disease stage, or comorbidities between the groups. It should be mentioned that the mean time between diagnosis

Table 1 Baseline demographic and clinical characteristics of the study population

\begin{tabular}{|c|c|c|c|}
\hline & Control group $(n=15)$ & Prehabilitation group $(n=14)$ & $p$-value \\
\hline Age (years), mean \pm SD & $63.8 \pm 7.6$ & $65.1 \pm 10.2$ & 0.689 \\
\hline BMI $\left(\mathrm{kg} / \mathrm{m}^{2}\right)$, mean $\pm \mathrm{SD}$ & $27.2 \pm 5.7$ & $29.3 \pm 6.1$ & 0.360 \\
\hline \multicolumn{4}{|l|}{ Disease stage, $n$ (\%) } \\
\hline III & $8(53.3)$ & $7(50.0)$ & \multirow[t]{2}{*}{0.858} \\
\hline IV & $7(46.7)$ & $7(50.0)$ & \\
\hline \multicolumn{4}{|l|}{ Medical history, n (\%) } \\
\hline Heart disease & $2(13.3)$ & $1(7.1)$ & 0.584 \\
\hline Diabetes & $2(13.3)$ & $3(21.4)$ & 0.564 \\
\hline Anticoagulation & $2(13.3)$ & $0(0)$ & 0.157 \\
\hline Smoking & $6(40.0)$ & $3(21.4)$ & 0.270 \\
\hline Alcohol & $2(13.3)$ & $0(0)$ & 0.157 \\
\hline \multicolumn{4}{|l|}{ ASA class, $n(\%)$} \\
\hline$\|$ & $6(40.0)$ & $9(64.3)$ & \multirow[t]{3}{*}{0.323} \\
\hline III & $8(53.3)$ & $5(35.7)$ & \\
\hline IV & $1(6.7)$ & $0(0)$ & \\
\hline $\begin{array}{l}\text { Time between diagnosis and interval surgery } \\
\text { (weeks), mean } \pm \text { SD [range] }\end{array}$ & $15.3 \pm 3.2[11.3-24.3]$ & $13.5 \pm 2.0[11.4-18.0]$ & 0.097 \\
\hline
\end{tabular}

ASA American Society of Anesthesiologists, BMI body mass index, COPD chronic obstructive pulmonary disease, SD standard deviation 
and interval cytoreductive surgery was shorter in the prehabilitation group than in controls (13.5 vs. 15.3 weeks, $p=0.097$ ). During this time period, patients were on NACT treatment, and the intervention group followed the prehabilitation recommendations. Thus, control patients required more time on NACT before the surgery was performed, although it was not statistically significant.

The results comparing the impact of the prehabilitation program on nutritional parameters are shown in Table 2. Prehabilitation group patients received a preoperative carbohydrate loading; however, this was not associated with an increased intraoperative risk of hyperglycemia $(p=0.668)$, nor postoperative insulin requirement $(p=0.782)$. In addition, the mean value of preoperative Hb1Ac was not different between the groups $(p=0.382)$, and no significant differences in serum total proteins, albumin, prealbumin, and hemoglobin levels were noted at diagnosis.

In contrast, the prehabilitation group showed higher preoperatively protein levels compared to the control group (7.4 vs. 6.8, $p=0.004$ ). In addition, postoperative serum total proteins and albumin values were higher in the prehabilitation group $(p=0.005$ and $p=$ 0.021 , respectively). Although not significant, a trend to higher postoperative levels of prealbumin and hemoglobin was also detected in the prehabilitation group.
Figure 1 shows the total serum protein value evolution in the control and prehabilitation groups.

Regarding the impact of the prehabilitation program on surgical and intraoperative parameters, no significant differences in length of surgery or surgical procedure complexity between the groups were observed (Table 3). However, although preoperative hemoglobin levels were similar between the groups, the prehabilitation group showed a significantly lower intraoperative blood transfusion rate (14.3\%) compared with the control group $(53.3 \%)(p=0.027)$, as well as a trend towards lower intraoperative vasoactive drug requirement $(7.1 \%$ vs. $20.0 \%$ ). The incidence of intraoperative complications showed a trend towards fewer complications in the prehabilitation group ( $40 \%$ of patients in the control group vs. $14.3 \%$ in the prehabilitation group).

When considering the postoperative outcomes, no significant differences regarding the length of stay, time to start adjuvant chemotherapy, and postoperative pain control between the groups were observed. Additionally, prehabilitation was not associated with increased risk of postoperative complications, reintervention, readmission rate, or mortality, although one patient in the control group died due to severe postoperative complications and none in the prehabilitation group. To note, the incidence of postoperative complications was similar between the groups, according to the Clavien-Dindo classification.

Table 2 Impact of the prehabilitation program on nutritional parameters

\begin{tabular}{|c|c|c|c|c|}
\hline & & Control group $(n=15)$ & $\begin{array}{l}\text { Prehabilitation group } \\
(n=14)\end{array}$ & $p$-value \\
\hline Preoperative HbA1c (\%) & & $5.6 \pm 0.6$ & $5.8 \pm 0.6$ & 0.382 \\
\hline Intraoperative glucose (BMTest) (mg/dl) & & $162.7 \pm 38.0$ & $154.7 \pm 53.5$ & 0.668 \\
\hline Postoperative insulin requirement, $n$ (\%) & & $5(33.3 \%)$ & $4(28.6 \%)$ & 0.782 \\
\hline \multirow[t]{4}{*}{ Diagnosis } & Total protein (g/dl) & $6.7 \pm 0.7$ & $6.8 \pm 0.4$ & 0.510 \\
\hline & Albumin (g/dl) & $3.9 \pm 0.5$ & $3.9 \pm 0.4$ & 0.959 \\
\hline & Prealbumin (mg/dl) & $15.6 \pm 6.2$ & $14.2 \pm 6.6$ & 0.683 \\
\hline & Hemoglobin (g/dl) & $12.0 \pm 1.8$ & $12.2 \pm 1.6$ & 0.843 \\
\hline \multirow[t]{4}{*}{ Preoperative } & Total protein (g/dl) & $6.8 \pm 0.5$ & $7.4 \pm 0.3$ & 0.004 \\
\hline & Albumin (g/dl) & $4.1 \pm 0.5$ & $4.4 \pm 0.3$ & 0.209 \\
\hline & Prealbumin (mg/dl) & $20.2 \pm 4.9$ & $22.4 \pm 4.3$ & 0.428 \\
\hline & Hemoglobin (g/dl) & $10.8 \pm 1.0$ & $10.8 \pm 0.9$ & 0.915 \\
\hline \multirow[t]{4}{*}{ Postoperative } & Total protein (g/dl) & $4.3 \pm 0.7$ & $4.9 \pm 0.6$ & 0.005 \\
\hline & Albumin (g/dl) & $2.4 \pm 0.6$ & $2.8 \pm 0.4$ & 0.021 \\
\hline & Prealbumin (mg/dl) & $9.5 \pm 3.3$ & $12.5 \pm 4.3$ & 0.124 \\
\hline & Hemoglobin (g/dl) & $9.5 \pm 1.0$ & $8.9 \pm 1.3$ & 0.164 \\
\hline \multirow[t]{4}{*}{ One month postoperative } & Total protein (g/dl) & $7.0 \pm 0.7$ & $7.2 \pm 0.5$ & 0.693 \\
\hline & Albumin (g/dl) & $4.2 \pm 0.5$ & $4.2 \pm 0.4$ & 0.985 \\
\hline & Prealbumin (mg/dl) & $20.7 \pm 8.2$ & $22.2 \pm 5.3$ & 0.465 \\
\hline & Hemoglobin (g/dl) & $11.2 \pm 1.0$ & $11.2 \pm 1.4$ & 0.683 \\
\hline
\end{tabular}




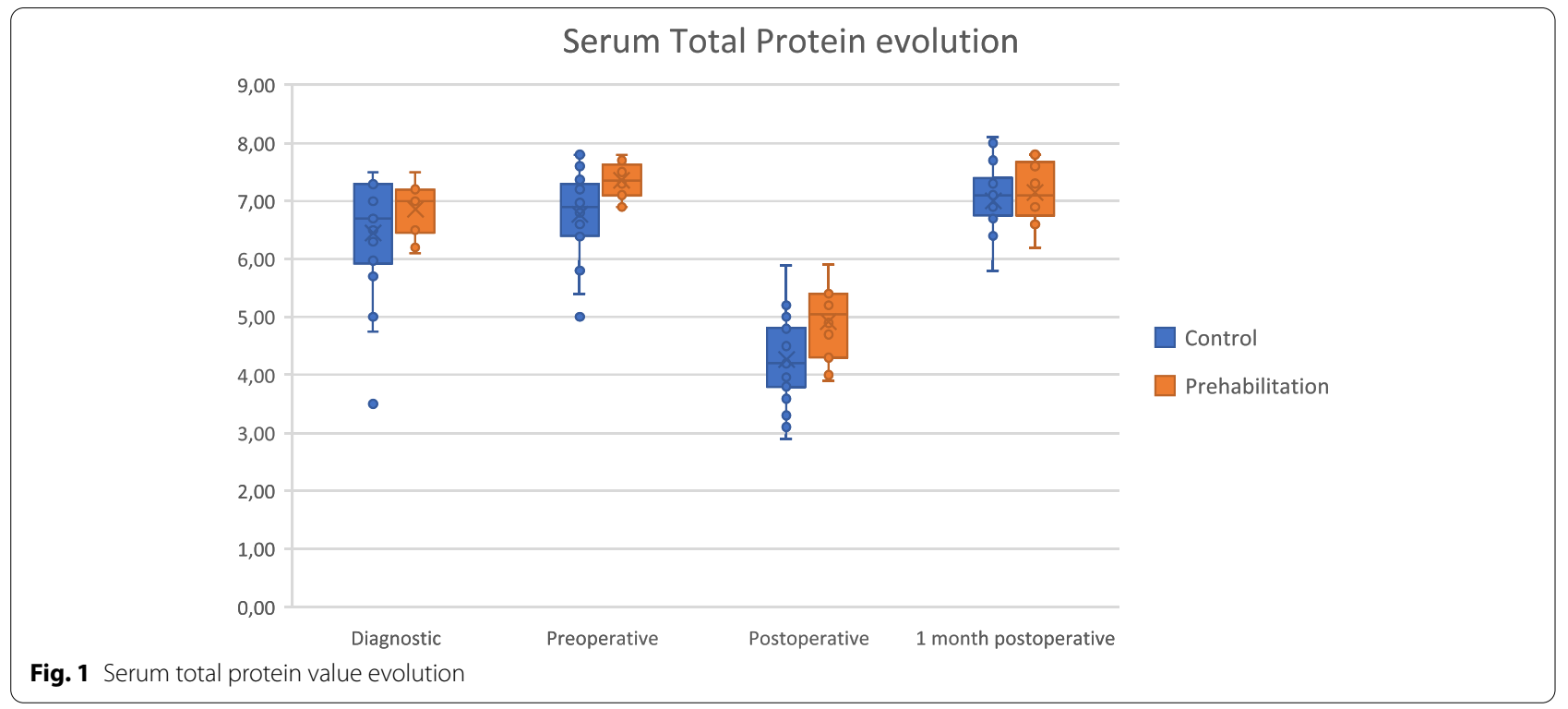

Table 3 Intraoperative and surgical outcomes

\begin{tabular}{|c|c|c|c|}
\hline & Control group $(n=15)$ & Prehabilitation group $(n=14)$ & $p$-value \\
\hline \multicolumn{4}{|l|}{ Surgical approach } \\
\hline Laparoscopic & $2(13.3)$ & $0(0)$ & 0.157 \\
\hline Laparotomic & $13(86.7)$ & $14(100)$ & \\
\hline Intestinal resection & $1(6.7)$ & $2(14.3)$ & 0.501 \\
\hline Epidural anesthesia & $11(73.3)$ & $11(78.6)$ & 0.742 \\
\hline Surgical time $(\mathrm{min})$ mean $\pm S D$ & $309.0 \pm 76.7$ & $300.0 \pm 87.7$ & 0.770 \\
\hline Aletti's SCS, mean \pm SD & $5.0 \pm 1.2$ & $5.1 \pm 2.6$ & 0.927 \\
\hline Intraoperative blood transfusion & $8(53.3)$ & $2(14.3)$ & 0.027 \\
\hline Intraoperative vasoactive drugs & $3(20.0)$ & $1(7.1)$ & 0.316 \\
\hline Intraoperative complications & $6(40.0)$ & $2(14.3)$ & 0.122 \\
\hline Vascular & $3(20.0)$ & $1(7.1)$ & 0.316 \\
\hline Intestinal & $2(13.3)$ & $1(7.1)$ & 0.584 \\
\hline Urological & $1(6.7)$ & $1(7.1)$ & 0.960 \\
\hline Cardiovascular & $0(0)$ & $0(0)$ & - \\
\hline
\end{tabular}

Data are presented as $n$ (\%), unless otherwise specified

SCS surgical complexity score, SD standard deviation

Furthermore, the prehabilitation group showed a trend towards earlier postoperative diet restart compared with the control group (1.3 days vs. 1.7 days). All postoperative and functional results are shown in Table 4.

\section{Discussion}

This pilot study reported our initial experience in implementing a prehabilitation program for ovarian cancer patients undergoing NACT and interval cytoreductive surgery, being the first study assessing the impact of a prehabilitation intervention. The main results showed a nutritional improvement among patients included in the prehabilitation group that may contribute to reduce perioperative complications and also to improve postoperative recovery.

Prehabilitation programs consist of the patient's preparation between diagnosis and surgery to improve functional capacity and metabolic reserves before intervention. Previous studies have shown that multimodal prehabilitation programs in major cancer surgeries have a positive impact on the patients' outcomes [13, 14].

Patients in the prehabilitation group showed higher pre- and postoperative serum total protein and postoperative albumin levels. Given that baseline nutritional 
Table 4 Postoperative outcomes

\begin{tabular}{|c|c|c|c|}
\hline & $\begin{array}{l}\text { Control group, mean } \pm \text { SD ( } n \\
=15)\end{array}$ & $\begin{array}{l}\text { Prehabilitation group, mean } \pm \text { SD } \\
(n=14)\end{array}$ & $p$-value \\
\hline Hospital stay (days) & $7.8 \pm 6.8$ & $7.4 \pm 5.0$ & 0.700 \\
\hline ICU stay (days) & $1.2 \pm 0.6$ & $1.2 \pm 0.9$ & 0.959 \\
\hline Time to start CT of surgery day (days) & $39.9 \pm 14.3$ & $37.4 \pm 9.2$ & 0.602 \\
\hline Pain VAS day 1 & $1.6 \pm 1.7$ & $1.7 \pm 1.7$ & 0.856 \\
\hline Pain VAS day 2 & $1.2 \pm 1.0$ & $1.4 \pm 1.4$ & 0.736 \\
\hline Diet restart (days) & $1.7 \pm 0.8$ & $1.3 \pm 0.6$ & 0.169 \\
\hline Deambulation restart (days) & $3.1 \pm 1.2$ & $2.9 \pm 1.4$ & 0.678 \\
\hline \multicolumn{4}{|l|}{ Postoperative complications, $n$ (\%) } \\
\hline Non reported & $6(40.0)$ & $4(28.6)$ & 0.518 \\
\hline Reported & $9(60.0)$ & $10(71.4)$ & \\
\hline \multicolumn{4}{|l|}{ Postoperative complications } \\
\hline Paralytic ileus & $2(13.3)$ & $1(7.1)$ & 0.584 \\
\hline Surgical site infection (superficial and deep) & $6(40.0)$ & $5(35.7)$ & 0.812 \\
\hline Surgical site infection (organ and space) & $2(13.3)$ & $0(0)$ & 0.157 \\
\hline Anastomosis breakdown & $2(13.3)$ & $0(0)$ & 0.157 \\
\hline Cardiovascular & $1(6.7)$ & $0(0)$ & 0.326 \\
\hline Respiratory & $3(20.0)$ & $1(7.1)$ & 0.316 \\
\hline Neurological & $0(0)$ & $2(14.3)$ & 0.129 \\
\hline Urinary tract infection & $4(26.7)$ & $1(7.1)$ & 0.164 \\
\hline Multiorgan failure & $1(6.7)$ & $0(0)$ & 0.326 \\
\hline Surgical reintervention & $1(6.7)$ & $1(7.1)$ & 0.960 \\
\hline \multicolumn{4}{|l|}{ Clavien-Dindo complications } \\
\hline I & $4(26.7)$ & $4(28.6)$ & 0.486 \\
\hline$\|$ & $10(66.7)$ & $8(57.1)$ & \\
\hline III & $0(0)$ & $1(7.1)$ & \\
\hline IV & $0(0)$ & $1(7.1)$ & \\
\hline V & $1(6.7)$ & $0(0)$ & \\
\hline Readmissions & $2(13.3)$ & $3(21.4)$ & 0.564 \\
\hline
\end{tabular}

CT chemotherapy, ICU intensive care unit, SD standard deviation, VAS visual analog scale

parameters at diagnosis were similar between the groups, the combination of both physical exercise and protein supplements $30 \mathrm{~min}$ after exercise training could have enhanced muscle hypertrophy and impacted body mass composition and nutritional status. In this line, in patients with rectal cancer having neoadjuvant chemoradiotherapy, prehabilitation was linked to an increase in patients' muscle mass [20].

Overall, up to $40 \%$ of controls showed intraoperative complications vs. $14.3 \%$ of patients in the prehabilitation group; however, the potential role of nutritional status on reducing perioperative and postoperative complications is still under investigation. Interestingly, $2(13.3 \%)$ patients in the control group presented anastomosis breakdown, while no patients in the intervention group suffered this postoperative complication. Whether anastomosis breakdown and other postoperative complications could be related to poor nutrition status is a hypothesis that cannot be ruled out. It should be taken into account that complications after surgery are related to surgical parameters but also depend on patient factors [21]. A study of patients with colorectal cancer resection showed no significant beneficial reduction in postoperative complications following nutritional supplementation, although patients who received whey protein supplementation 4 weeks before surgery had a mean improvement in functional walking capacity [22]. Similarly, a prospective randomized study in nonmalnourished patients undergoing abdominal cancer surgery showed that patients who received nutritional supplementation for 14 days before surgery significantly reduced postoperative complications. The laboratory parameters decreased in the control group, and in the nutritional supplementation group, they were stable (albumin and total protein) or raised (transferrin and total lymphocyte count) after surgery [23]. Besides, protein supplementation alone has been shown to improve nutritional parameters. Yi et al. randomized 118 patients 
undergoing elective surgery for gynecological cancer to preoperative carbohydrate-only loading versus whey protein-infused carbohydrate loading. The whey proteininfused carbohydrate loading group had shorter hospital stay, lower readmission rate within 1 month, lower weight loss, lower C-reactive protein/albumin ratio, preserved muscle mass, and better handgrip strength when compared to the preoperative carbohydrate-only loading group [24].

In our study, an improvement in preoperative nutritional status was observed. In this way, several studies in advanced ovarian cancer patients correlated a low serum preoperative albumin and prognostic nutritional index with a worse overall survival $[25,26]$. In addition, two prospective studies about major abdominal surgery correlated an early postoperative serum albumin and total protein drop with postoperative complications [27, 28]. Overall, poor preoperative nutritional status reflects poor postoperative nutritional status, which is associated with higher postoperative morbidity. Moreover, a review of Obermair et al. suggests that receiving perioperative nutritional interventions $1-2$ weeks prior to surgery and nutritional interventions of early postoperative feeding can reduce the length of hospital stay and postoperative complications in gynecological cancer patients undergoing major surgery [29].

Overall, preoperative carbohydrate loading has been shown to be an effective method to control postoperative insulin resistance $[30,31]$. However, data are limited concerning the effects of carbohydrate loading on preoperative hyperglycemia and insulin management in patients with ovarian cancer patients previous to interval cytoreductive surgery. This study adds evidence for recommending routine preoperative carbohydrate loading. Preoperative carbohydrate loading in our prehabilitation group was not associated with intraoperative increased risk of hyperglycemia, postoperative insulin requirement neither intraoperative nor postoperative complications. Similarly, Alimena et al. reported that carbohydrate loading was associated with an increase in preoperative glucose values without impacting the complication rates [31].

Our results also showed that the prehabilitation program was safe with no adverse events or increase of perioperative complications. Although there are few studies available about prehabilitation and postoperative complications, published data suggest a potential benefit of the prehabilitation program in terms of postsurgical readmissions rates and postoperative complications [13, 32]. Systematic reviews and meta-analysis of prehabilitation programs for patients undergoing major abdominal surgery and oncologic surgery reported that prehabilitation programs are feasible and safe with a protective factor for postoperative complications [33-36].

Interestingly, our results showed that the prehabilitation group reported significantly lower requirements of intraoperative blood transfusion rate and a trend towards lower intraoperative vasoactive drug requirement. In this line, a randomized control trial of patients submitted to elective major abdominal surgery also showed a trend toward lower requirements of vasoactive drugs during surgery in the prehabilitation group $(p=0.053)$ [13]. This fact could suggest that prehabilitation would improve tolerability during surgery avoiding hypotension and hypovolemic shock.

Although the recommended length for a prehabilitation period is 2-4 weeks before surgery [15], in the present study, the length of the prehabilitation program was larger, since depended on patients' disease and individual response to NACT. The period on NACT treatment is a great opportunity to improve functional capacity through a prehabilitation program. Given that type of surgical intervention, surgical complexity, and clinical characteristics were well-balanced between the groups, the duration of the prehabilitation mainly depended on NACT tolerance and toxicity. Interestingly, a shorter time between diagnosis and interval cytoreductive surgery in the prehabilitation group was observed suggesting a better tolerability to chemotherapy in prehabilitated patients. Other studies also demonstrated that prehabilitation program during neoadjuvant treatment is feasible, safe, and well-tolerated in patients with esophagogastric cancer and it has positive effects in increasing exercise capacity before surgery and lower risks of postoperative pneumonia $[10,11,32,37]$.

\section{Strengths and weaknesses}

This study has several strengths that deserve to be commented on. To our knowledge, this is the first study assessing the impact of prehabilitation programs in patients with ovarian cancer undergoing interval cytoreductive surgery after NACT. Moreover, in our center, prehabilitation program is a routine preoperative assessment of gynecologic oncologic patients before surgery. Additional strengths include an homogeneous study population both at demographics and clinical characteristics with advanced-stage ovarian cancer patients undergoing interval cytoreductive surgery after 3 cycles of NACT.

On the other hand, potential weaknesses of our study include the non-randomized control trial design and the inherent limitations associated with a retrospective study, where some data or complications may have been missed. However, the enrollment of all consecutive patients reduced the chance of selection bias, and clinical stage and comorbidities were well matched between the 
groups. In addition, it was a pilot study with small sample size and, therefore, limited statistical power. As this was a preliminary study, the sample size was decided arbitrarily, and the results may not be able to properly detect the precise differences. Besides, the single-center design may have limited the generalizability of the results. However, a qualitative data collection method was used before surgery to ensure that patients included in the final analysis followed prehabilitation recommendations. Although no formal data analysis of adherence and acceptability was performed due to the clinical setting of the study, the study results may be feasibly imputed to the prehabilitation program.

Finally, it has to be noted that the COVID-19 outbreak may have had an impact on the results, given that organizational aspects of healthcare providers were truncated by this pandemic and the study was carried out in two different scenarios. Besides, the physical and psychological impacts of lockdown on patients included cannot be ruled out.

\section{Implications for practice and future research}

Our findings seem to suggest preoperative and postoperative nutritional improvements in prehabilitated patients, but given the preliminary nature of the design, this study is mainly intended to stimulate further investigations to assess the efficacy of surgical prehabilitation in gynecologic oncology patients, specifically in patients with ovarian cancer. Our findings warrant future prospective evaluation and support the investigation of prehabilitation programs. Moreover, the study provides data contributing to the larger body of evidence and also for eventual reviews or meta-analysis to help clarify the value of prehabilitation programs in ovarian cancer patients.

Future larger and adequately powered studies will help to evaluate the effect of prehabilitation on postoperative surgical, physical, and metabolic outcomes, while investigating tolerance to NACT and oncologic outcomes and periodically evaluate success with quality improvement initiatives. Finally, although standardized prehabilitation guidelines for ovarian cancer patients need to be established, we encourage all groups to prehabilitate ovarian cancer patients undergoing interval cytoreductive surgery, based on the ERAS guidelines.

\section{Conclusions}

In conclusion, a trimodal prehabilitation program comprising exercise, nutritional supplementation, and psychological support administered during NACT may improve the patient's nutritional status and, therefore, be associated with a better postoperative recovery in patients with advanced-stage ovarian cancer before interval cytoreductive surgery. The period during neoadjuvant treatment is a great opportunity to improve the patient's functional capacity through a prehabilitation program.

\section{Abbreviations}

SPSS: Statistical Package for Social Sciences; NACT: Neoadjuvant chemotherapy; ERAS: Enhanced Recovery After Surgery; ICU: Intensive care unit; SGS: Surgical complexity score; SD: Standard deviation.

\section{Acknowledgements}

The authors would like to acknowledge the multidisciplinary team that collaborates with the prehabilitation program.

\section{Authors' contributions}

Study concepts: EM, GM, CRC, and MDM. Study design: EM, JMSS, AT, GM, and CRC. Data acquisition: BF, EM, and JMSS. Quality control of data and algorithms: BF and MDM. Data analysis and interpretation: EM, GM, JSS, and CRC. Statistical analysis: EM. Manuscript preparation: EM, BF, and GM. Manuscript editing: CRC, AT, and MDM. Manuscript review: EM, JMSS, CRC, AT, MDM, BF, and GM. The authors read and approved the final manuscript.

\section{Authors' information}

Twitter handle: @ester_miralpeix (Ester Miralpeix).

Funding

There was no funding for this study.

\section{Availability of data and materials}

The datasets generated and/or analyzed during the current study are not publicly available but are available from the corresponding author (Miralpeix, Ester) on reasonable request.

\section{Declarations}

\section{Ethics approval and consent to participate}

The study was evaluated and approved by the institutional Ethics Committee of the Hospital del Mar (Institutional Review Board Project No. 2017/7770/I). All participants provided a written informed consent.

\section{Consent for publication}

Not applicable

\section{Competing interests}

The authors declare that they have no competing interests.

\section{Author details}

${ }^{1}$ Department of Obstetrics and Gynecology, Hospital del Mar, Universitat Autònoma de Barcelona, Passeig Marítim 25-29, E-08003 Barcelona, Spain. ${ }^{2}$ Universitat Pompeu Fabra, Barcelona, Spain. ${ }^{3}$ Department of Anesthesia, Hospital del Mar, Barcelona, Spain. ${ }^{4}$ Department of Medical Oncology, Hospital del Mar, Barcelona, Spain. ${ }^{5}$ Cancer Research Program, IMIM (Hospital del Mar Institute of Medical Research), Barcelona, Spain. ${ }^{6}$ Department of Endocrinology, Hospital del Mar, Barcelona, Spain.

Received: 29 October 2021 Accepted: 10 February 2022 Published online: 23 February 2022

\section{References}

1. Holschneider CH, Berek JS. Ovarian cancer: epidemiology, biology, and prognostic factors. Semin Surg Oncol. 2000;19:3-10 https://doi.org/10. 1002/1098-2388(200007/08)19:1<3:.:aid-ssu2>3.0.co;2-s.

2. Armstrong DK, Alvarez RD, Bakkum-Gamez JN, Barroilhet L, Behbakht K, Berchuck A, et al. NCCN Guidelines Insights: ovarian cancer, version 
1.2019. J Natl Compr Canc Netw. 2019;17:896-909. https://doi.org/10. 6004/jnccn.2019.0039.

3. Nakamura K, Kitahara Y, Nishimura T, Yamashita S, Kigure K, Ito I, et al. Nadir CA-125 serum levels during neoadjuvant chemotherapy and no residual tumor at interval debulking surgery predict prognosis in advanced stage ovarian cancer. World J Surg Oncol. 2020;18(1):200. https://doi.org/10.1186/s12957-020-01978-6.

4. Fagotti A, Ferrandina MG, Vizzielli G, Pasciuto T, Fanfani F, Gallotta V, et al. Randomized trial of primary debulking surgery versus neoadjuvant chemotherapy for advanced epithelial ovarian cancer (SCORPIONNCT01461850). Int J Gynecol Cancer Off J Int Gynecol Cancer Soc. 2020;30:1657-64. https://doi.org/10.1136/ijgc-2020-001640.

5. Vergote I, Coens C, Nankivell M, Kristensen GB, Parmar MKB, Ehlen T, et al. Neoadjuvant chemotherapy versus debulking surgery in advanced tubo-ovarian cancers: pooled analysis of individual patient data from the EORTC 55971 and CHORUS trials. Lancet Oncol. 2018;19:1680-7. https:// doi.org/10.1016/S1470-2045(18)30566-7.

6. Fadadu PP, Polen-De CL, McGree ME, Weaver AL, Moynagh MR, Takahashi $\mathrm{N}$, et al. Patients triaged to neoadjuvant chemotherapy have higher rates of sarcopenia: an opportunity for prehabilitation. Gynecol Oncol. 2021;160:40-4. https://doi.org/10.1016/j.ygyno.2020.10.025.

7. Gillis C, Carli F. Promoting perioperative metabolic and nutritional care. Anesthesiology. 2015;123:1455-72. https://doi.org/10.1097/ALN.00000 00000000795

8. Geisler JP, Linnemeier GC, Thomas AJ, Manahan KJ. Nutritional assessment using prealbumin as an objective criterion to determine whom should not undergo primary radical cytoreductive surgery for ovarian cancer. Gynecol Oncol. 2007;106:128-31. https://doi.org/10.1016/j.ygyno. 2007.03.008.

9. Komiyama S, Nagashima M, Taniguchi T, Rikitake T, Morita M. Metastasis to para-aortic lymph nodes cephalad to the renal veins in patients with ovarian cancer. World J Surg Oncol. 2020;18(1):64. https://doi.org/10. 1186/s12957-020-01841-8.

10. West MA, Loughney L, Lythgoe D, Barben CP, Sripadam R, Kemp GJ, et al. Effect of prehabilitation on objectively measured physical fitness after neoadjuvant treatment in preoperative rectal cancer patients: a blinded interventional pilot study. Br J Anaesth. 2015. https://doi.org/10.1093/bja/ aeu318.

11. Halliday LJ, Doganay E, Wynter-Blyth V, Osborn H, Buckley J, Moorthy K. Adherence to pre-operative exercise and the response to prehabilitation in oesophageal cancer patients. J Gastrointest Surg Off J Soc Surg Aliment Tract. 2021;25:890-9. https://doi.org/10.1007/s1 1605-020-04561-2

12. Li C, Carli F, Lee L, Charlebois P, Stein B, Liberman AS, et al. Impact of a trimodal prehabilitation program on functional recovery after colorectal cancer surgery: a pilot study. Surg Endosc Other Interv Tech. 2013;27:1072-82. https://doi.org/10.1007/s00464-012-2560-5.

13. Barberan-Garcia A, Ubré M, Roca J, Lacy AM, Burgos F, Risco R, et al. Personalised prehabilitation in high-risk patients undergoing elective major abdominal surgery. Ann Surg. 2018;267:50-6. https://doi.org/10.1097/ SLA.0000000000002293.

14. Minnella EM, Bousquet-Dion G, Awasthi R, Scheede-Bergdahl C, Carli F Multimodal prehabilitation improves functional capacity before and after colorectal surgery for cancer: a five-year research experience. Acta Oncol (Madr). 2017;56:295-300. https://doi.org/10.1080/0284186X.2016.1268268.

15. Miralpeix E, Mancebo G, Gayete S, Corcoy M, Solé-Sedeño J-M. Role and impact of multimodal prehabilitation for gynecologic oncology patients in an Enhanced Recovery After Surgery (ERAS) program. Int J Gynecol Cancer. 2019;29:1235-43. https://doi.org/10.1136/ijgc-2019-000597.

16. Miralpeix E, Nick AM, Meyer LA, Cata J, Lasala J, Mena GE, et al. A call for new standard of care in perioperative gynecologic oncology practice: impact of enhanced Recovery After Surgery (ERAS) programs. Gynecol Oncol. 2016;141:371-8. https://doi.org/10.1016/j.ygyno.2016.02.019.

17. Nelson G, Bakkum-Gamez J, Kalogera E, Glaser G, Altman A, Meyer $L A$, et al. Guidelines for perioperative care in gynecologic/oncology: Enhanced Recovery After Surgery (ERAS) Society recommendations-2019 update. Int J Gynecol Cancer. 2019;29:651-68. https://doi. org/10.1136/ijgc-2019-000356.

18. Clavien PA, Barkun J, de Oliveira ML, Vauthey JN, Dindo D, Schulick RD, et al. The Clavien-Dindo classification of surgical complications: five-year experience. Ann Surg. 2009;250:187-96. https://doi.org/10.1097/SLA. 0b013e3181b13ca2.
19. Aletti GD, Dowdy SC, Podratz KC, Cliby WA. Relationship among surgical complexity, short-term morbidity, and overall survival in primary surgery for advanced ovarian cancer. Am J Obstet Gynecol. 2007;197:676.e1-7. https://doi.org/10.1016/j.ajog.2007.10.495.

20. Moug SJ, Barry SJE, Maguire S, Johns N, Dolan D, Steele RJC, et al. Does prehabilitation modify muscle mass in patients with rectal cancer undergoing neoadjuvant therapy? A subanalysis from the REx randomised controlled trial. Tech Coloproctol. 2020;24:959-64. https://doi.org/10. 1007/s10151-020-02262-1.

21. Llueca A, Serra A, Climent MT, Segarra B, Maazouzi Y, Soriano M, et al. Outcome quality standards in advanced ovarian cancer surgery. World $J$ Surg Oncol. 2020;25:309. https://doi.org/10.1186/s12957-020-02064-7.

22. Gillis C, Loiselle SE, Fiore JF, Awasthi R, Wykes L, Liberman AS, et al. Prehabilitation with whey protein supplementation on perioperative functional exercise capacity in patients undergoing colorectal resection for cancer: a pilot double-blinded randomized placebo-controlled trial. J Acad Nutr Diet. 2016;116:802-12. https://doi.org/10.1016/j.jand.2015.06. 007.

23. Kabata P, Jastrzebski T, Kakol M, Krol K, Bobowicz M, Kosowska A, et al. Preoperative nutritional support in cancer patients with no clinical signs of malnutrition-prospective randomized controlled trial. Support Care Cancer. 2015;23:365-70. https://doi.org/10.1007/s00520-014-2363-4.

24. Yi HC, Ibrahim Z, Abu Zaid Z, Daud Z'AM, Yusop NBM, Omar J, et al. Impact of enhanced recovery after surgery with preoperative whey protein-infused carbohydrate loading and postoperative early oral feeding among surgical gynecologic cancer patients: an open-labelled randomized controlled trial. Nutrients. 2020;12. https://doi.org/10.3390/ nu12010264.

25. Kumar A, Torres ML, Cliby WA, Kalli KR, Bogani G, Aletti G, et al. Inflammatory and nutritional serum markers as predictors of peri-operative morbidity and survival in ovarian cancer. Anticancer Res. 2017;37:3673-7. https://doi.org/10.21873/anticanres.11738.

26. Feng Z, Wen $H$, Ju X, Bi R, Chen $X$, Yang W, et al. The preoperative prognostic nutritional index is a predictive and prognostic factor of highgrade serous ovarian cancer. BMC Cancer. 2018;18:883. https://doi.org/10. 1186/s12885-018-4732-8.

27. Labgaa I, Joliat G-R, Kefleyesus A, Mantziari S, Schäfer M, Demartines N, et al. Is postoperative decrease of serum albumin an early predictor of complications after major abdominal surgery? A prospective cohort study in a European centre. BMJ Open. 2017;7:e013966. https://doi.org/ 10.1136/bmjopen-2016-013966

28. Hübner M, Mantziari S, Demartines N, Pralong F, Coti-Bertrand P, Schäfer M. Postoperative albumin drop is a marker for surgical stress and a predictor for clinical outcome: a pilot study. Gastroenterol Res Pract. 2016;2016:8743187. https://doi.org/10.1155/2016/8743187.

29. Obermair A, Simunovic M, Isenring L, Janda M. Nutrition interventions in patients with gynecological cancers requiring surgery. Gynecol Oncol. 2017;145:192-9. https://doi.org/10.1016/j.ygyno.2017.01.028.

30. Gianotti L, Biffi R, Sandini M, Marrelli D, Vignali A, Caccialanza R, et al. Preoperative oral carbohydrate load versus placebo in major elective abdominal surgery (PROCY): a randomized, placebo-controlled, multicenter, phase III trial. Ann Surg. 2018;267:623-30. https://doi.org/10.1097/ SLA.0000000000002325.

31. Alimena S, Falzone M, Feltmate CM, Prescott K, Contrino Slattery L, Elias K. Perioperative glycemic measures among non-fasting gynecologic oncology patients receiving carbohydrate loading in an enhanced recovery after surgery (ERAS) protocol. Int J Gynecol Cancer Off J Int Gynecol Cancer Soc. 2020;30:533-40. https://doi.org/10.1136/ijgc-2019-000991.

32. Dewberry LC, Wingrove $L$, Marsh MD, Glode AE, Schefter TE, Leong S, et al. Pilot prehabilitation program for patients with esophageal cancer during neoadjuvant therapy and surgery. J Surg Res. 2019;235:66-72. https://doi.org/10.1016/j.jss.2018.09.060.

33. Moran J, Guinan E, McCormick P, Larkin J, Mockler D, Hussey J, et al. The ability of prehabilitation to influence postoperative outcome after intra-abdominal operation: a systematic review and meta-analysis. Surg (United States). 2016;160:1189-201. https://doi.org/10.1016/j.surg.2016. 05.014

34. Luther A, Gabriel J, Watson RP, Francis NK. The impact of total body prehabilitation on post-operative outcomes after major abdominal surgery: a systematic review. World J Surg. 2018;42:2781-91. https://doi.org/10. 1007/s00268-018-4569-y. 
35. Hijazi Y, Gondal U, Aziz O. A systematic review of prehabilitation programs in abdominal cancer surgery. Int J Surg. 2017;39:156-62. https://doi.org/ 10.1016/j.jisu.2017.01.111.

36. Schneider S, Armbrust R, Spies C, du Bois A, Sehouli J. Prehabilitation programs and ERAS protocols in gynecological oncology: a comprehensive review. Arch Gynecol Obstet. 2020;301:315-26. https://doi.org/10.1007/ s00404-019-05321-7.

37. Argudo N, Rodó-Pin A, Martínez-Llorens J, Marco E, Visa L, MessaggiSartor M, et al. Feasibility, tolerability, and effects of exercise-based prehabilitation after neoadjuvant therapy in esophagogastric cancer patients undergoing surgery: an interventional pilot study. Dis Esophagus Off J Int Soc Dis Esophagus. 2021;34. https://doi.org/10.1093/dote/doaa086.

\section{Publisher's Note}

Springer Nature remains neutral with regard to jurisdictional claims in published maps and institutional affiliations.

- fast, convenient online submission

- thorough peer review by experienced researchers in your field

- rapid publication on acceptance

- support for research data, including large and complex data types

- gold Open Access which fosters wider collaboration and increased citations

- maximum visibility for your research: over $100 \mathrm{M}$ website views per year

At BMC, research is always in progress.

Learn more biomedcentral.com/submissions 